Military Technical College, Kobry El-Kobbah. Cairo, Egypt

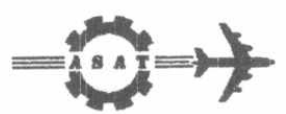

$9^{\text {th }}$ International Conference

On Aerospace Sciences \&

Aviation Technology

\title{
THE MULTICHANNEL ADAPTIVE ANTENNA ARRAYS FOR SIMULTANEOUS DETECTION OF BEARING ANGLES OF NUMEROUS EMISSION SOURCES
}

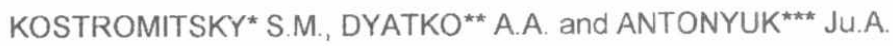

\section{ABSTRACT}

The methods are proposed for simultaneous detection of number, position and wave front form for antenna focusing on numerous emission sources without of traditional scanning of the space with the help of linear or two-dimensional antenna arrays. The decisions are based on the autoregressive (AR) and autoregressive moving average (ARMA) methods of received signals spectrum modeling and new regularized parametric target model fitting (PTMF) approach. A computer simulation data are presented.

"Professor, Special Designer's Bureau "Kamerton", Institute of Applied Physics, National Academy of Sciences, Minsk, Republic of Belarus.

** Associate Professor, Institute of Applied Physics, National Academy of Sciences, Minsk, Republic of Belarus.

***Associate Professor, Military Academy, Minsk, Republic of Belarus 


\section{The Introduction}

The AAD radar protection against anti-radar missiles and other high-accuracy weapons is the actual task. The best way to decide it is to keep the radar transmitter being turned off. In order to make it possible till some time the introduction into radar of the passive information channel is needed. The development of new approaches of passive radar design leads the finding of the number of new methods of passive detection, angle bearing and tracking. Some of them, for example, the methods using the full problem of correlation matrix' eigenvalues solving are not so useful for practice because of strong dependence of coordinates (bearing) estimation accuracy upon the decision on the number of tracking targets exactness. As for us, the better and more natural way is to make this decision by the standard threshold procedure as the first, and to use the simple adaptation algorithms as the second. So, we have: to detect the number of targets in passive mode (with the use of the own target illuminations), to track them and to estimate at least, the angles of the target (azimuth or(and) elevation, for example).

Our researches detected the possibility of using of special Adaptive Antenna Arrays (AAA) with:

1) the processors based on the spatial spectrums of received signals modeling by the rational transfer functions:

2) the processors based on the parametrical modeling of received signals.

In this paper because of absence of the enough room we'll describe only the bearing and tracking components of discussed problem. The task of detection will be discussed separately.

\section{The Theory}

Let's begin reviewing the first direction. Among the methods of given direction it is expedient to allocate modeling of a spectrum of spatial frequencies of received signals by a model of an autoregression (AR) Kostromitsky et al $[1,2,4]$ and autoregression moving average (ARMA), Kostromitsky, Zaitsev [3]. If the signal of each source has a narrow-band spectrum which is not overlapped with spectra of remaining signals, and spatially - uncorrelated noise is rather small, the resulting spatial spectrum of antenna' received signal has a brightly expressed spades character. Thus, the position of some peak on axis of spatial frequencies characterizes both angular position of the appropriate radiation source, and the phase-to-amplitude distributions (PAD) on aperture of an antenna system, generated by this radiation source.

So, let the input signal of a $\mathrm{N}$-element linear equidistant antenna array be presented as an AR-process, order $\mathrm{M}$, where $\mathrm{M}$ - an amount of radiation sources (or their expected amount).

$$
S_{k}=-\sum_{m=1}^{M} c_{m} S_{k-m}
$$

and $S_{i}$ - the received signal of $i$-th element of antenna array.

In this case, as shown in (4), the spatial spectrum of an input signal $S(z)$ can be presented as

$$
S(z)=\frac{1}{A(z)}
$$

where 


$$
A(z)=\sum_{m=0}^{M} c_{m} z^{-m}=B \prod_{m=0}^{M}\left(1-w_{m} z^{-1}\right)
$$

$z_{m}=\frac{1}{w_{m}}$-the roots of $A(z)$ polynomial, $z=\exp (-i k d \sin \theta), k=\frac{2 \pi}{\lambda}$ - the wavenumber, $d-$ interelement spacing of an array, $\theta$ - an angle of a deviation from the normal to array center.

As it is visible from (3), the transfer function of a bleaching input signal filter $A(z)$ describes the pattern forming circuit (PFC) of AAA. This function is possible to be presented as transfer function of a $\mathrm{m}$-cascade discrete differentiating filter, output signal of which has an aspect to within insignificant factor:

$$
e(z)=A(z) S(z)=\prod_{M=1}^{M}\left(1-w_{m} z^{-1}\right) S(z) .
$$

Passing in (4) from an image to a pre-image, it is simple to achieve an expression of a signal of $n$-th the element of $m$-th the cascade of spatial derivation

$$
S_{m, n}=S_{m-1, n}-w_{m} S_{m-1, n-1}
$$

where $S_{m-1, n}$ and $S_{m-1, n}$ - signals of $n$-th and n-1-th output elements of the m-1-th cascade of spatial derivation. The structure of PFC, realizing (5), is shown on fig. 1a, it is a well-known Davies beamformer, Hudson [8].

Thus the bleaching (in relation to a spectrum of spatial frequencies of an input signal) filter is a spatial differentiating filter of the order $M$, representing, in case of the discrete aperture, by some PFC with complex weight factors. Each weight factor $w_{m}$ module determines a width, and its phase - a position of rejection zone in the field of spatial frequencies. Thus the factors $c_{m}$ can be defined under the Vieta formulas for weight factors $w_{\mathrm{m}}$

Thus, the posed problem is reduced to the definition of weight factors $w_{m}$ realizing a bleaching spatial filter for an input signal. Let's consider a solution of this problem by methods of the theory of an optimal filtration. Let's copy expression (1) as:

$$
S=S^{\prime} C(W)+\xi(t),
$$

where $S=\left\{S_{1}, S_{2} \ldots S_{n-m}\right\}^{T}$ - the vector of an input signal,

$$
S^{\prime}=\left[\begin{array}{l}
S_{2}, S_{3}, \ldots S_{M+1} \\
S_{3}, S_{4}, \ldots S_{M+2} \\
S_{N-M+1} \ldots S_{N}
\end{array}\right],
$$

$C(W)=\left\{C_{1}, C_{2} \ldots C_{M}\right\}^{T}$-vector of Vieta factors, being a nonlinear function of weight factor $W=\left\{w_{1}, w_{2}, \ldots w_{M}\right\}^{T}, \xi(t)$ - noise of observation with a correlation matrix $N_{\xi}$. 
For the definition of the optimal meaning of $\mathrm{W}$, the linearization of the observation equation (6) is needed. Let's decompos 2 it in a point of an evaluation $\hat{W}$ in a Taylor series and limit the first two terms, Goryunov, Soskovets [5]

$$
S=H W+U+\xi(t),
$$

where $H=\left.S^{\prime} \frac{\partial C}{\partial W_{T}}\right|_{W=\dot{W}}$ - linearizing matrix, $U=S^{\prime} C(\hat{W})-H \hat{W}$.

Choosing a widely spreaded model of Wiener process with the equation of a condition

$$
\frac{d W}{d t}=\eta(t)
$$

where $\eta(t)$ - is a complex white Gaussian noise with a correlation matrix $N_{\eta}$, is simple to achieve the equation of an optimal filtration of the weight vector

$$
\frac{d \hat{W}}{d t}=R H^{+} N_{\xi}^{-1} E
$$

and equation of a correlation matrix of errors of a filtration

$$
\frac{d R}{d t}=N_{\eta}-R H^{+} N_{\xi}^{-1} H R
$$

where $E=S-S^{\prime} C(\hat{W})$ - output PFC signal, representing an instantaneous error of a prediction of an input antenna array signal, + - a symbol of Hermitian conjugation. The expressions (8) and (9) completely describe the adaptation algorithm of AAA based on AR-modeling of input signal' spatial spectrum. However essential shortages caused by the need for significant signal-to-noise rations in input signals $(10 \ldots 20 \mathrm{~dB}$ on the antenna element) are inherent in the given approach. The application of ARMA - modeling allows to lower the requirements to a power level of input signals, but thus a realization of a signal processor, (fig. 2) becomes considerably complicated. Besides the unremovable problems of the AR- and ARMA-modeling approaches are:

1) a difficulty of passage to two-dimensional antenna systems, that is connected to necessity of operation of an identification of bearings;

2) a difficulty of the transformation of a problem solution for the Fresnel diffraction zone operation;

3) an essential dependence of an adaptation time upon a correlation properties of received signals

Natural direction of AAA processors perfecting, in these conditions, is the passage to parametrical modeling of accepted signals. It is known as a parametrical target model fitting, Nickel [7], that under condition of full received signal correlation in borders of an antenna system the input antenna array signal can be noted in the following aspect 


$$
Z=S(W)+\xi(t)=F W_{a}+\xi(t)
$$

where $S(W)$ - the vector of a useful signal, being a nonlinear function of a vector of parameters $W$;

$W=\left\{W_{x}, W_{y}, W_{R}, W_{a}\right\}$ - vector of parameters consisting of vectors, describing an angular coordinates $x, y$, distance $R$ and complex amplitudes a of the radiating sources in a basic adaptive antenna array channel;

$F$ - "instantaneous" phazor matrix, composed of $W_{x}, W_{y}, W_{R}$ vectors.

Considering a problem of the definition of a parameters vector $W$ on an received field $Z$ as an inverse problem of a radiation Goryunov, Soskovets [5], being a nonlinear incorrect problem, it is expedient to use the methods of the theory of a solution of incorrect problems, Bakushinsky, Goncharsky [6]. In this case, received signal Z is subjected to transformation by the regularizing operator $R_{\alpha}$ in a form of

$$
Y=R_{\alpha} Z=\left[H^{+} H+\alpha I\right]^{-1} H^{+} Z,
$$

where $H=\left.\frac{\partial s(W)}{\partial W^{T}}\right|_{W=\hat{W}}$,

$\alpha$ - the regularization factor which is matched to the spatially-uncorrelated noise $\xi$ power.

In this case, the gradient adaptation algorithm has an aspect:

$$
\frac{d \hat{W}}{d t}=\mu R_{\alpha}[Z-S(\hat{W})]
$$

where $\mu$-amplification factor chosen from conditions of the desirable dynamic properties.

Taking into account, that $S(\hat{W})$ is a known signal,

$$
R_{\alpha} S(W) \approx \lim _{\alpha \rightarrow 0} R_{\alpha} S(\hat{W})=\left[\frac{0}{\hat{W}_{a}}\right] .
$$

Substituting expression (13) in (12), we shall receive the final operating algorithm of a regularized AAA processor, which structure is shown on fig. 3 :

$$
\frac{d \hat{W}}{d t}=\mu\left\{R_{\alpha} Z-\left[\frac{0}{\hat{W}_{a}}\right]\right\} .
$$

Synthesized regularized adaptive processor has obvious physical treatment. Let's consider in a linear approximation a transformation of an input signal $S(W)$, decomposing it in Taylor series and limiting linear terms:

$$
R_{\alpha} S(W) \approx R_{\alpha}[S(\hat{W})+H(W-\hat{W})]=\left[\frac{W_{F}-\hat{W}_{F}}{W_{a}}\right]
$$


where $W_{F}$ - unenergetic components of a vector of parameters $W$ (everything, except $\left.W_{a}\right)$

For example for trivial array in a Fraunhofer diffraction zone

$$
R_{\alpha} S(W)=\left[\begin{array}{l}
W_{x}-\hat{W}_{x} \\
W_{y}-\hat{W}_{y} \\
W_{a}
\end{array}\right] .
$$

Obviously, that in this case (expression (14)) the output signal of a regularizing operator has three groups of components:

1) $\quad W_{a}-$ is a true factorized estimation of the complex amplitudes of radiating sources signals, permitting to treat the appropriate outputs as the output signals, obtained from the independent PFC with the antenna patterns, maxims of which are oriented on the "own" stimulus sources, and in direction on remaining radiants have falls. Obviously, the signals from these outputs can be subjected for temporal processing,

2) $W_{x}-\hat{W}_{x}$ and $W_{y}-\hat{W}_{y}$ - the outputs of "differential" PFC for $x$ and $y$ coordinates accordingly.

Such a representation of a signal, transformed by the regularizing operator $R_{a}$, allows to consider the synthesized regularized AAA processor shown on fig. 3 as multichannel adaptive analog of the classical direction finder with a phase instantaneous comparison of signals.

\section{The Computer Simulation results}

During a computer simulation of the developed algorithms of a multibeam detection both self-focusing the quite satisfactory outcomes were achieved for AR-modeling algorithm (thie example result is shown on fig. 1b), and for the PTMF algorithm - on fig. 4a. The simulation was carried out in the identical conditions of simultaneous work with five targets, the true position of the targets is shown in terms of interelement phase shifts by dashed lines on the lower graphs. The advantages of PTMFalgorithm are obvious.

The example results on two-dimensional PTMF-processor computer simulation is shown on fig. $4 \mathrm{~b}$. The left column of digits on the lower graphs determines the processor degrees of freedom number and the right column - the number of a target. Obviously, the confusing of $\mathrm{x}$ and $\mathrm{y}$ interelement phase shifts estimations for each target is impossible.

\section{The Conclusion.}

In an outcome of the brief review of several types of the AAA processors it is possible to make a conclusion, that most acceptable for a practical realization and meeting the requirements to passive radar system, nowadays is represented as a regularized PTMF processor. In the cases when only one angle for example, for the energy focusing in Fraunhofer diffraction zone is needed, the AR- and ARMA-processors have an advantage because of their simplicity. 


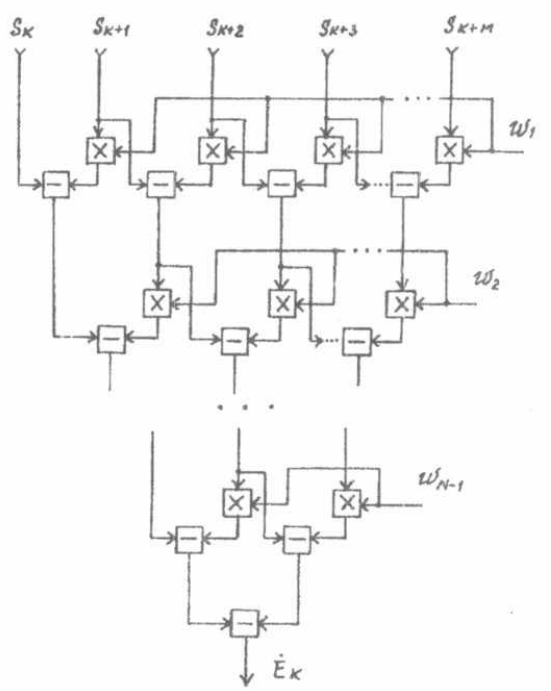

a)

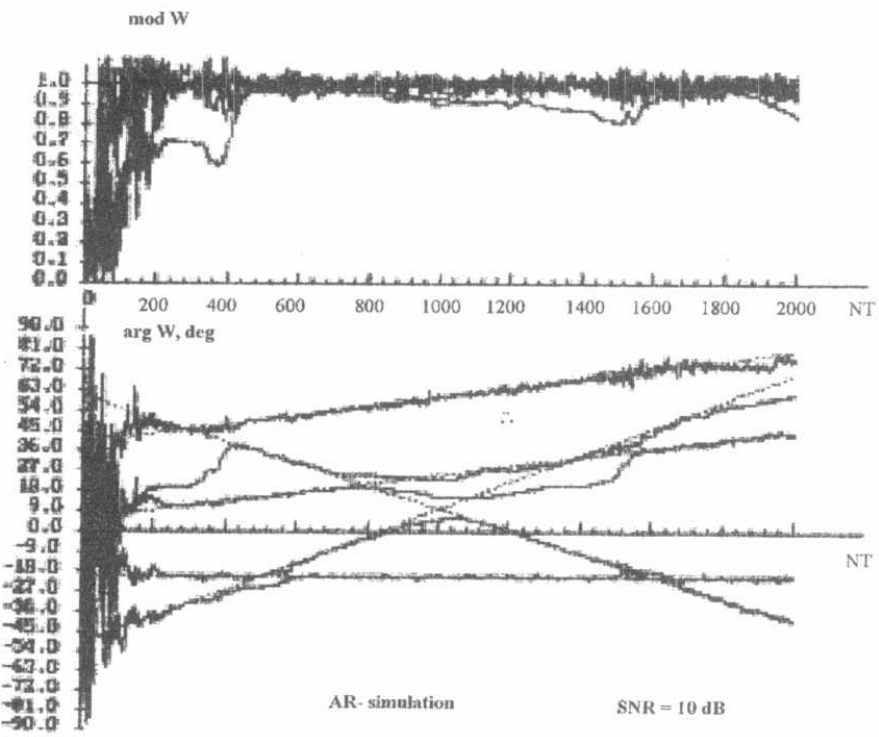

b)

Fig. 1 


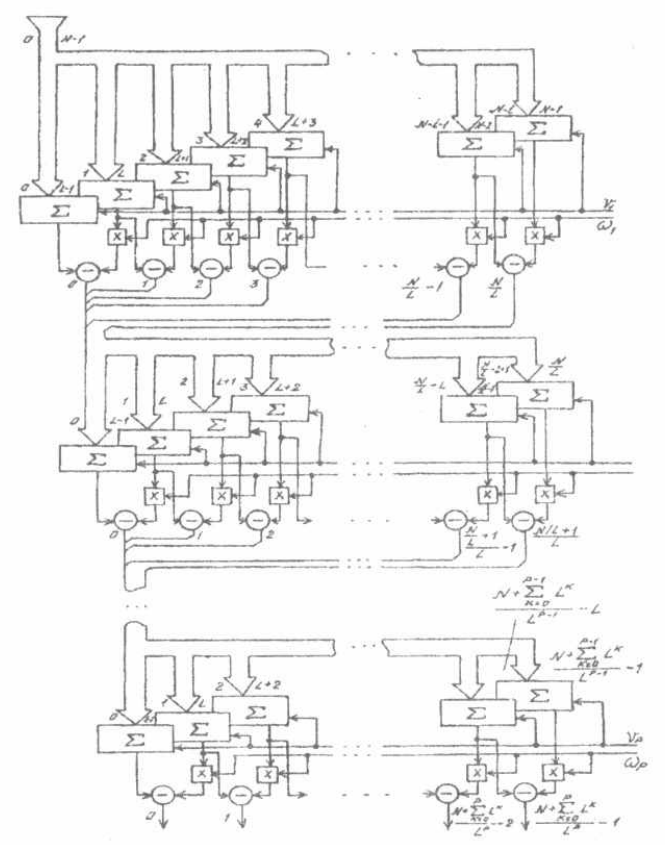

Fig. 2

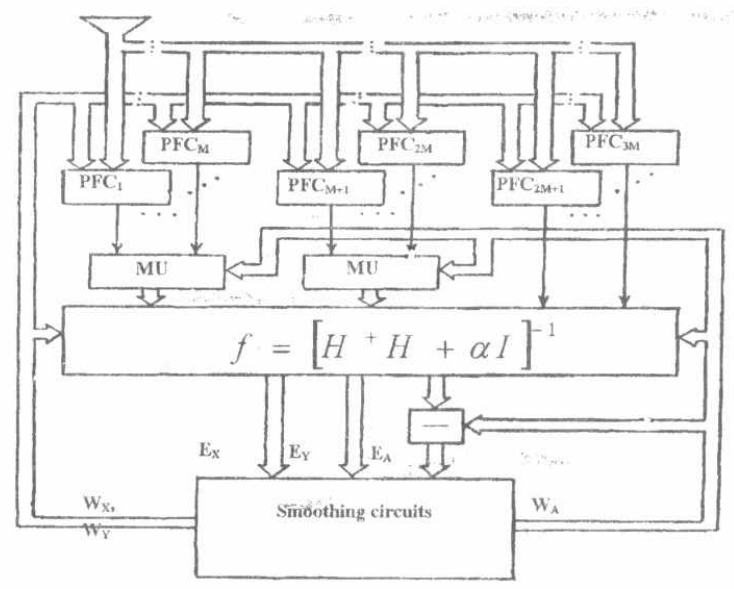

Fig. 3 


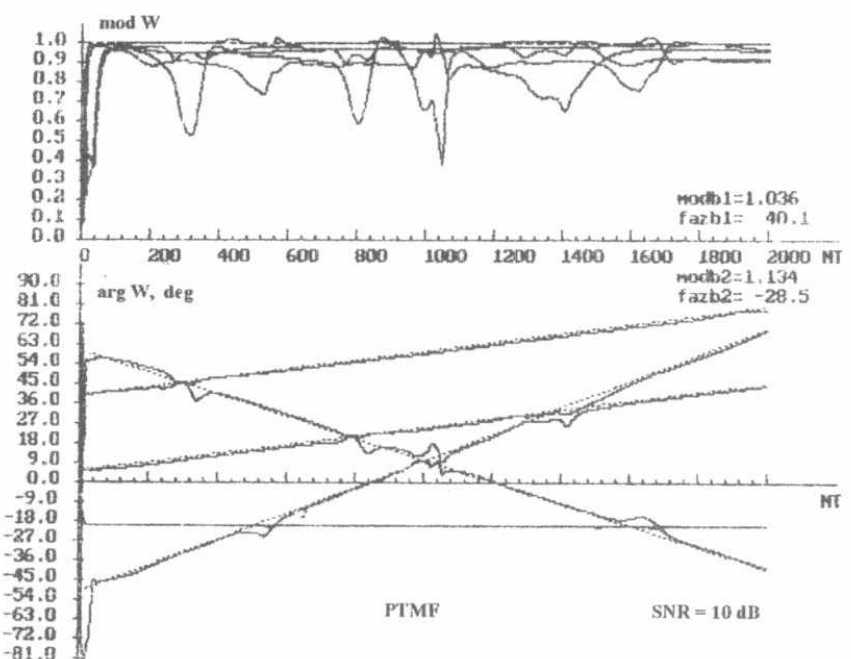

a)

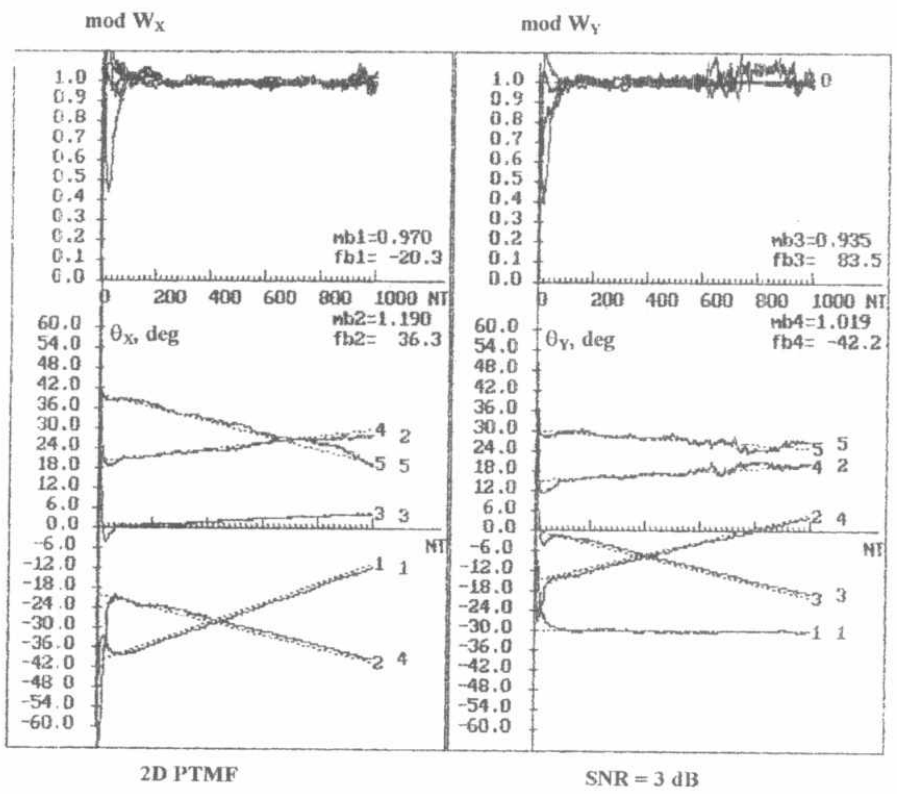

b)

Fig. 4 


\section{References.}

1. Kostromitsky S.M., Dyatko A.A., Okhrimenko A.E. The Adaptive Antenna Array with complex Self-Tuning, separating signals from different directions.// 1989 , Radioengineering, №1, Moscow, 11 pp.

Костромицкий С.М., Дятко А.А., Охрименко А.Е. Адаптивная антенная решетка с комплексной самонастройкой для разделения сигналов, приходящих с различных направлений. //1989, Радиотехника № 1, 11 рp.

2. Kostromitsky S.M., Dyatko A.A., Tyulpakov V.N. The Investigation of the processors of Multibeam Adaptive Antenna Arrays// 1991, Radiophysics, Moscow Institute on Radioengineering, National Academy of Sciences, $12 \mathrm{pp}$.

Костромицкий С.М., Дятко А.А., Тюльпаков В.Н. Исследование процессоров многолучевых адаптивных антенных решеток. //1991, Радиофизика. М.: МРТИ $\mathrm{AH}$ CCCP, $12 \mathrm{pp}$.

3. Zaitsev A.G., Kostromitsky S.M. The Multibeam Self-focussing Adaptive Antenna Array based on Autoregressive Moving Average model.//1993, The Radioengineering and Electronics. Republican scientific Almanac №22, Minsk, Institute on Radioengineering, $9 \mathrm{pp}$.

Зайцев А.Г., Костромицкий С.М. Многолучевая СФААР на основе модели авторегрессии скользящего среднего. //1993, Радиотехника и электроника: Респ. межведомств. сб. научн. тр. Вып. 22/МРТИ. -Мн.: Выш. шк., 9 рр.

4. Antonyuk Ju.A., Dyatko A.A. The usage of Calman Filtering Methods in the tasks of multitarget self-focussing with the separation of the signals on the base of autoregressive model.// 1993, The Radioengineering and Electronics. Republican scientific Almanac №22, Minsk, Institute on Radioengineering, 8 pp.

Антонюк Ю.А., Дятко А.А. Применение методов калмановской фильтрации в задачах многоцелевой автофокусировки с разделением сигналов на основе

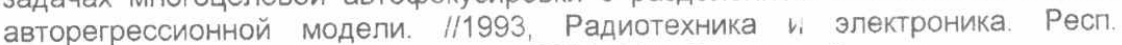
межведомств. сб. научн. тр. Вып. 22 ІМРТИ.- Мн.: Выш. шк., 8 рр.

5. Goryunov A.A., Soskovets A.V. Inverse tasks of dissipation in acoustics. 1989, Moscow State University, 112 pp.

Горюнов А.А., Сосковец А.В. Обратные задачи рассеяния в акустике. 1989, - М.: Издательство МГУ, $112 \mathrm{pp}$.

6. Bakushinsky A.B., Goncharsky A.V. Incorrect Tasks. Numerical methods and applications. 1989, Moscow State University, 198 pp.

Бакушинский А.Б., Гончарский А.В. Некорректные задачи. Численные методы и приложения. 1989 - М.: Издательство МГУ, 198 рр.

7. Nickel U. Angular Superresolution by Antenna Array Processing. //1989, L'Onde Electrique - Nov.-Dec. v.69, № 6, 11pp.

$8 . \quad H u d s o n$ J.E. Adaptive array principles. 1981, - Peter Peregrinus Ltd., Stevenage, UK and NY, $253 \mathrm{pp}$. 